\title{
Penggunaan Komik Berbasis Web pada Pelajaran Sejarah Siswa SMA
}

\author{
Wildana Harismawan ${ }^{1)}$ \\ Teknologi Pendidikan, Fakultas Ilmu Pendidikan, Universitas Negeri Malang \\ Jl. Semarang No.5, Sumbersari, Kec. Lowokwaru, Kota Malang, Jawa Timur 65145 \\ Email: wildanaharismawan.1801216@students.um.ac.id
}

\begin{abstract}
Abstrak
Kemajuan ilmu pengetahuan dan teknologi, khususnya di bidang teknologi informasi sangat berpengaruh terhadap keefektivan pembelajaran. Kemajuan tersebut memungkinkan munculnya alternatif baru yang dapat dimanfaatkan oleh guru untuk menggunakan media pembelajaran variatif di kelas. Perkembangan komik, khususnya komik digital beberapa tahun ini berkembang dengan pesat. Berdasarkan sifatnya, media komik pembelajaran mempunyai sifat sederhana, mudah dipahami oleh siswa. Tujuan dari penelitian telaah ini adalah mengetahui kelayakan media pembelajaran berbasis komik digital pada pembelajaran sejarah siwsa SMA. Hasil penelitian pembelajaran menggunakan media komik berbasis Web, yaitu dapat meningkatkan minat serta mempermudah peserta didik untuk memahami materi sejarah yang dianggap membosankan.
\end{abstract}

Kata kunci: Pembelajaran Sejarah, Komik Pembelajaran, Komik Berbasis Web

\section{The Use of Web-Based Comics in High School History Subjects}

\author{
Wildana Harismawan ${ }^{1)}$ \\ Teknologi Pendidikan, Fakultas Ilmu Pendidikan, Universitas Negeri Malang \\ Jl. Semarang No.5, Sumbersari, Kec. Lowokwaru, Kota Malang, Jawa Timur 65145 \\ Email: wildanaharismawan.1801216@students.um.ac.id
}

\begin{abstract}
Advances in science and technology, especially in the field of information technology, greatly affect the effectiveness of learning. This progress allows for many alternative choices that can be utilized by teachers to use varied media in classroom learning. The development of comics lately is very significant indeed. Based on its nature, comic learning media has a simple nature, easily understood by students. Learning with comic media is expected to increase the interest of students to better understand the boring historical material. The purpose of this development research is to produce and know the feasibility of comic-based learning media for Senior High School students.
\end{abstract}

Keywords: Historical Learning, Learning Comics, Web Based Comics 


\section{PENDAHULUAN}

Setiap bangsa atau negara sudah pasti memiliki sejarahnya masing-masing yang menggambarkan perjuangannya pada masa lampau, salah satunya adalah perjuangan melawan penjajahan. Sejarah perjuangan pada masa lalu yang dialami suatu bangsa, dapat dibuktikan melalui benda-benda bersejarah seperti dokumen, rekaman suara, foto, monumen, dan lain-lain. Kisah perjuangan melawan penjajahan tersebut pernah dialami oleh bangsa ini. Indonesia pernah dijajah oleh bangsa-bangsa lain seperti Belanda dan Jepang, sebelum akhirnya bersatu menjadi sebuah negara besar seperti saat ini.

Pembelajaran sejarah merupakan pembelajaran yang wajib disematkan di setiap jenjang baik di jenjang SD, SMP maupun SMA. Namun kenyataannya pendidikan di Indonesia masih sering mengalami permasalahan dari berbagai aspek, salah satunya adalah minimnya inovasi dalam pembelajaran sejarah. Padahal sejarah merupakan materi wajib yang harus dikuasai oleh setiap siswa, sebagai bentuk kencintaan terhadap tanah air dan penghormatan kepada jasa para pahlawan yang telah gugur. Materi sejarah yang disampaikan oleh pengajar kebanyakan masih menggunakan buku dengan tulisan berderet, sehingga menyebabkan kejenuhan peserta didik.

Berkaitan dengan masalah tersebut, guru dituntut memiliki Hakikat dari pendidikan itu berarti memberi tuntunan kepada perkembangan manusia sehingga mencapai kedewasaan jasmani dan rohani. Meskipun manusia telah mendapatkan pendidikan sejak kecil, di Indonesia baru mengenal pendidikan pada abad ke-5 (Leo Agung, 2012: 03). THA Perserikatan Bangsa- Bangsa, dengan keputusan yang dibuat pada tahun 1993, terlalu menekankan pada percepatan pekerjaan dalam pendidikan hak asasi manusia di semua negara dan menyarankan bahwa orang- orang yang seharusnya dididik adalah guru dan siswa terutama (Kepenekçi, 1999: 213).

Sasaran, yang ingin dicapai oleh komunitas modern dalam hubungan di antara orang-orang, adalah untuk mendidik orang agar menghormati hak asasi manusia sebagai anggota masyarakat. Salah satu prasyarat untuk mencapai tujuan ini adalah agar peserta didik memiliki sikap positif terhadap pendidikan ini. Karena sadar akan hak asasi manusia, mengadopsi dan membela hak-hak ini terkait erat dengan sikap yang dianggap sebagai komponen utama kepribadian (Kuzgun, 1981: 102).

Desakan permanen dan sepihak pada proses pengambilan keputusan yang rasional dan masuk akal sangat kontraproduktif untuk proses pembelajaran yang substansial. Melainkan harus diasumsikan bahwa penilaian yang kompeten muncul dari berbagai proses akuisisi sebelumnya. Dalam hal ini, proses pendidikan selalu harus memberikan pendekatan sensual, fisik dan emosional untuk siswa (lih. Meyer 1992, 511). Kalau tidak, perasaan tersebar, bahwa pengetahuan yang diperoleh hanya berguna untuk sekolah, tetapi tidak relevan untuk "kehidupan nyata". Oleh karena itu, hubungan yang erat antara konsep kehidupan sehari-hari dan konsep ilmiah merupakan kebutuhan penting untuk proses pembelajaran berkelanjutan. "Dalam pengertian yang paling umum, pandangan kontemporer tentang pembelajaran adalah bahwa orang membangun pengetahuan dan pemahaman baru berdasarkan apa yang sudah mereka ketahui dan percayai" (Bransford antara lain, 2000, 10).

Kinerja anak-anak yang buruk di sekolah dan sikap apatis terhadap sekolah telah dikaitkan dengan minat baca yang buruk, kebiasaan, dan lingkungan, terutama metode pengajaran yang buruk, 
seperti metode konvensional, yang melibatkan bacaan yang berpusat pada guru, bacaan individual, penglihatan dan kata-kata yang tampak dan instruksional. Metode konvensional bekerja dengan asumsi bahwa dalam semua hal belajar "guru paling tahu." Di sini perhatian lebih difokuskan pada apa yang diajarkan dan bukan pada anak. Para guru sering menggunakan metode tampilan dan ucapkan "repeat after me", biasanya tanpa alat bantu visual dan perlengkapan mengajar lainnya (Kalu, 2001 dan Farrant, 1980).

Membaca adalah alat yang sangat diperlukan untuk mencapai stabilitas emosional, menikmati waktu senggang, berbagi pengalaman sulit hidup yang ditulis dalam buku, dan mengikuti perkembangannya kejadian di dunia pada umumnya. Dengan keterampilan membaca, mata pelajaran lain dapat dipelajari secara efektif sekolah. Tujuan pertama dari pendidikan dasar adalah untuk menanamkan melek huruf dan angka tetap, dan kemampuan berkomunikasi secara efektif. Karena sisa dari sistem pendidikan dibangun di atas yang utama pendidikan, itu adalah kunci keberhasilan atau kegagalan seluruh sistem pendidikan (Ogunrombi dan Adio, 1995).

Motivasi membaca murid tergantung pada beberapa faktor motivasi yang mendorong membaca (Guthrie \& Alao, 1997; Guthrie, Wigfield \& VonSecker, 2000; Stipek, 1996), termasuk guru, keluarga, teman, buku, lingkungan, kegiatan (Ulper, 2011), teknik membaca, tingkat pemahaman membaca, minat baca (Kramarič, Ropič \& Urbančič Jelovšek, 2000), kecenderungan, kepercayaan dan tujuan (Conradi Gee Jang \& McKenna, 2014). Dengan menumbuhkan motivasi membaca intrinsik, guru mendorong membaca seumur hidup (Bucik, 2009) dan berkontribusi pada tingkat membaca yang lebih tinggi dan peningkatan prestasi akademik (Pečjak, Bucik, Gradišar \& Peklaj, 2006).

Siswa yang secara intrinsik lebih termotivasi dan kompeten dalam membaca memiliki guru yang menggunakan beragam bahan bacaan, mendorong membaca dan berdiskusi tentang konten, termasuk membaca dalam pelajaran dan membaca secara teratur di kelas, mempromosikan membaca di kelas, dan memberi siswa pilihan bahan bacaan ( Pečjak \& Košir, 2004). Dalam konteks ini pembelajaran menunjuk pada sebuah proses komunikasi antara pendidik dan media pembelajaran yang digunakan.

Dalam proses pembelajaran nantinya juga akan berjalan dengan maksimal jika pesan pembelajaran disampaikan secara jelas, runtut dan menarik (Yuni Maryuni, 2011:58). Pembelajaran, termasuk di dalamnya penguasaan dalam penggunaan media pembelajaran. Media yang menarik dapat menciptakan suasana yang aktif dan menyenangkan bagi siswa sehingga membangkitkan minat dan motivasi siswa untuk belajar.

Menurut Oktarini et al. (2014) media sangat berperan penting dalam proses pembelajaran sehingga pemilihan media oleh guru harus mempertimbangkan kesesuaiannya dengan materi dan kondisi siswa. Unsur penting dalam pembelajaran adalah metode dan media pembelajaran. Kedua aspek ini berkaitan, karena pemilihan salah satu metode mengajar tertentu akan mempengaruhi jenis media pembelajaran yang sesuai (Arsyad, 2007).

Sampai saat ini media pembelajaran sejarah kurang beragam, masih berupa buku dengan tulisan berderet disertai angka, masalah itu pula yang menjadi topik utama dalam Seminar Sejarah Nasional 2018 (Fawakih, 2018). Kondisi itu menyebabkan peserta didik mengalami kesulitan untuk 
mengingat waktu dalam peristiwa sejarah. Padahal sejatinya waktu merupakan bagian penting dalam sejarah, bahkan sejarah memiliki sifat yang sebagian besar berhubungan

dengan waktu, yaitu diakronis, ideografis, dan unik. Adanya waktu sesesuai fakta membedakan sejarah dengan sastra (Kuntowijoyo, 1995).

Keadaan yang disebutkan di atas menonjolkan masalah membangun strategi penilaian ilmiah dan pengetahuan yang memadai di bidang ilmu sosial, di antara para siswa. Masalah terjadi khususnya ketika konsep dan kompetensi penilaian yang ada didiskualifikasi atau bahkan dikeluarkan dari proses pembelajaran. Konsep kehidupan sehari-hari kemudian sering tetap sebagai konstruksi paling penting dari penilaian dan interpretasi, bahkan setelah instruksi ilmu sosial telah terjadi (lih. Schnotz 1998, 77).

Melihat kondisi tersebut dibutuhkan suatu gagasan untuk membuat media pembelajaran yang dapat meningkatkan efektifitas pembelajaran sejarah. Salah satu cara yang dapat digunakan Komik sebagai media mempunyai peranan sebagai alat yang mempunyai fungsi menyampaikan pesan pembelajaran. Gagasan itu muncul sebab pembelajaran akan lebih dimengerti dan dipahami oleh peserta didik (siswa) apabila didukung dengan media pembelajaran. Berkaitan dengan itu, dibutuhkannya alat bantu pembelajaran dalam usaha menciptakan proses belajar yang menyenangkan, menarik, interaktif dan efektif serta membantu siswa dalam memahami materi ajar menjadikan tujuan pembelajaran dapat tercapai dengan baik (Putra, 2013).

\section{KAJIAN LITERATUR}

Komik adalah salah satu genre sastra non- tradisional yang memiliki daya tarik khusus untuk anak laki-laki (Sadowski, 2010). Komik menarik pembaca ke dunia yang mereka baca dan memungkinkan mereka untuk bergaul dengan karakter, yang tampak nyata bagi pembaca. Ini menarik anak laki-laki untuk membaca dan berdampak pada minat mereka dalam membaca, perendaman dan perasaan kompetensi mereka (McCloud, 2010), yang merupakan komponen paling penting dari pemahaman membaca pada anak laki-laki (Pečjak, Bucik, Peštaj, Podlesek dan Pirc, 2010).

Penggunaan kartun dan komik dalam pengajaran dapat membangkitkan minat dan mendorong partisipasi dalam proses pembelajaran. Kartun adalah gambar persiapan; any sketsa atau desain besar di atas kertas, yang mewakili adegan dengan atau tanpa reproduksi suara, dan biasanya lucu. Di sisi lain, komik adalah serangkaian gambar yang menceritakan urutan cerita dalam bentuk gambar. Komik adalah ilustrasi, yang jika digambar berurutan, menceritakan sebuah kisah (World Book Encyclopedia, 2001 dan Robinson, 1981).

Namun demikian, menurut Akun Statistik 20112011 Korea Publication Culture Association (1), proporsi kartun di antara semua publikasi baru (44.036) adalah 14,61\% (6.433), dan mayoritas kartun anak-anak Menempati Ini berarti bahwa anak-anak adalah pembaca utama. Bahkan, menurut Survei Membaca Nasional 2011 (berdasarkan buku kertas), 2) Tidak seperti siswa sekolah menengah dan menengah dengan sedikit preferensi untuk kartun, siswa sekolah dasar lebih suka membaca $(17,7 \%)$ dan belajar kartun $(17,4 \%)$. , Preferensi untuk belajar kartun cukup tinggi untuk muncul dalam urutan kartun hiburan $(15,1 \%)$. 
Komik telah didefinisikan dalam hal bahasa, komunikasi, dan media visual yang kompleks. Terlepas dari perdebatan teoritis, suksesi konsep bergambar telah ada selama lebih dari satu milenium di mana ia diukir atau dilukis sebagai pada permadani dan hieroglif yang merupakan sistem awal untuk melambangkan dan mencatat informasi (Perry \& Aldridge, 1971). Pada abad ke-20, komik telah diterbitkan sebagai kartun editorial dalam bentuk cetak (Sabin, 2001). Disajikan untuk tujuan hiburan dan politik, komik didistribusikan baik koran harian atau mingguan. Selanjutnya, komik telah dikeluarkan ke berbagai format mulai dari lelucon, buku komik, intisari hingga novel grafis (Perry \& Aldridge, 1971, Sabin, 2001).

Penggunaan komik sebagai bahan terjemahan ruang kelas memiliki beberapa manfaat pendidikan. (Schwartz dan Rubinstein- Avila ,2006) berpendapat bahwa seorang pembaca akan mendapat manfaat pendidikan dari multimodality dalam melek buku komik. Mereka menyarankan agar siswa mengembangkan pemikiran kritis dan multidimensi melalui latihan dan negosiasi semiotika dalam buku komik. Ilustrasi komik adalah alat bantu visual, dan ilustrasi ini meningkatkan pemahaman penerjemah terhadap teks sumber. Gambar- gambar sebagai alat bantu visual dalam komik juga membantu penerjemah memahami dan menerjemahkan teks sumber dengan mengungkapkan siapa yang berbicara, siapa yang diam, siapa yang ragu untuk berbicara, yang menunjukkan emosi, dan sebagainya.

Kajian Marcel Bonnef (1998:8) mengenai Komik Indonesia juga menjadi salah satu referensi dalam penelitian ini. Menurut pandangannya komik mengandung aspek grafis dimaa para pembaca sulit membayangkan realitas dari buku bacaan biasa sehingga gambar komik dibuat sederhana agar setiap orang mampu mencernanya. Komik juga mampu menyumbang beberapa unsur yang berguna untuk menjawab masalah yang lebih umum saat ini, yaitu gambaran yang khas Indonesia.

Komik adalah gambar bergambar dan grafik disajikan dalam bentuk urutan yang ditujukan untuk mengirim informasi dan untuk menghasilkan jawaban atau kesimpulan bagi pembaca. Komik sudah memiliki lebih dari 100 tahun keberadaannya, dan selalu digunakan dengan sukses sebagai instrumen penyebaran gagasan dan utilitas publik dalam beberapa jenis kampanye. Komik memiliki kekhasan menggabungkan dua bentuk ekspresi budaya yang sangat kaya: sastra dan seni plastik, yang membuatnya menjadi alat pedagogik yang sangat efektif. Ketika sepenuhnya dieksplorasi, katakata dan ilustrasi memiliki kekuatan besar untuk menceritakan kisah dan untuk mengirimkan pesan (MacCloud, 1993).

Komik memiliki cerita yang sistematis dan teratur yang membuat mereka lebih mudah untuk mengikuti dan menghafal isinya (G. Rota and J. Izquierdo, 2003). Komik merupakan sebuah media pembelajaran yang unik dan menarik. Komik juga bersifat sederhana, jelas, dan mudah dipahami. Komik memiliki daya tarik tersendiri yang berupa perpaduan cerita dan gambar sehingga mudah dicerna dan tidak terkesan menggurui sehingga komik dapat dijadikan sebagai media pembelajaran. Komik merupakan suatu bentuk bacaan dimana peserta didik membacanya tanpa harus dibujuk (Ahmad Rohani, 1997:79).

Komik dapat membantu siswa dalam mengembangkan kemampuan berbahasa, kegiatan seni, dan peryataan kreatif dalam bercerita, dramatisasi, bacaan, penulisan, melukis dan menggambar, serta membantu mereka menafsirkan dan mengingat-ingat isi materi bacaan dari buku teks dari pada sifat yang hiburan sematamata (Sudjana dan Rivai, 2002). Selain itu dengan keunggulan di lingkungan 
digital,Horton (2008) telah mengklarifikasi bagaimana webcomics (seni berurutan diposting online) dengan cepat disusun oleh pencipta komik amatir dan profesional menggunakan Adobe Photoshop, Gimp, dan berbagai alat pengeditan grafis. Akhirnya, penggemar komik saat ini memiliki banyak pilihan untuk menerbitkan karya mereka di situs hosting komik publik seperti Comic Genesis, The Duck Comics, Smackjeeves, blog dan media sosial (Lamerichs, 2013; Mitkus, T. 2013).

Komik merupakan suatu realita yang bermakna, sebagian dari siswa akan mengenal dan mengingat karakter tokoh dari komik yang mereka lihat. Alasan lain dipilihnya media komik, karena media ini sangat menarik dalam kehidupan siswa dan banyak terdapat di toko- toko bacaan, bahkan sekarang komik sudah sangat mudah diakses melalui internet salah satunya komik melalui situs web. Dalam banyak jenis genre komik yang dapat dipilih oleh pembaca, namun masih sangat minim komik yang mengangkat tema pembelajaran maupun sejarah. Dengan adanya penelitian berupa komik berbasis web dalam pelajaran sejarah untuk siswa SMA kelas XI ini, ditujukan untuk menumbuhkan ketertarik siswa untuk mempelajari dan memahami sejarah sesuai dengan sifat-sifat sejarah. Selain itu dapat menumbuhkan budaya baru untuk membiasakan siswa mengetahui perjalanan sejarah, sehingga prinsip sejarah sebagai disiplin ilmu bisa diterapkan.

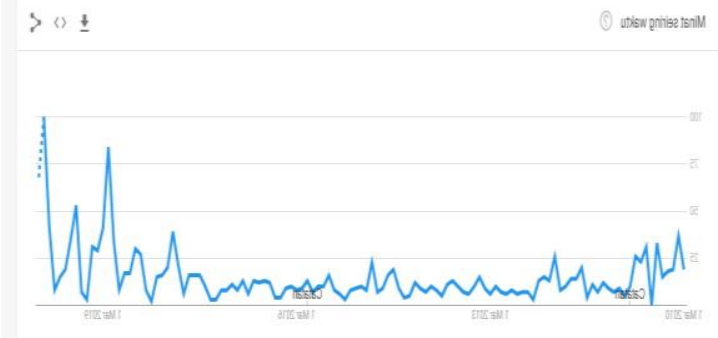

\section{Gambar 1. Grafik Minat Terhadap Komik Pendidikan di Indonesia Tahun 2010-2020}

Gambar 1 menunjukkan grafik popularitas komik pendidikan di Indonesia melalui penelusuran web yang dikutip dari Google Trends. Dari grafik tersebut, dapat dilihat bahwa popularitas komik pendidikan dari bulan Maret 2010 hingga April 2019 mengalami tingkat popularitas yang naik turun, namun tidak terlalu signifikan. Kemudian pada awal Maret 2019 komik pendidikan mulai mengalami peningkatan dan penurunan popularitas yang cukup signifikan hingga tahun 2020.

Dengan adanya data tersebut, dapat disimpulkan bahwa akhir akhir ini pencarian mengenai komik pendidikan mulai popular. Tentunya sudah banyak sumber-sumber yang dapat dijadikan sebagai pedoman penggunaan komik pendidikan dalam proses belajar mengajar. Sehingga dapat membantu guru dalam proses pembelajaran. 


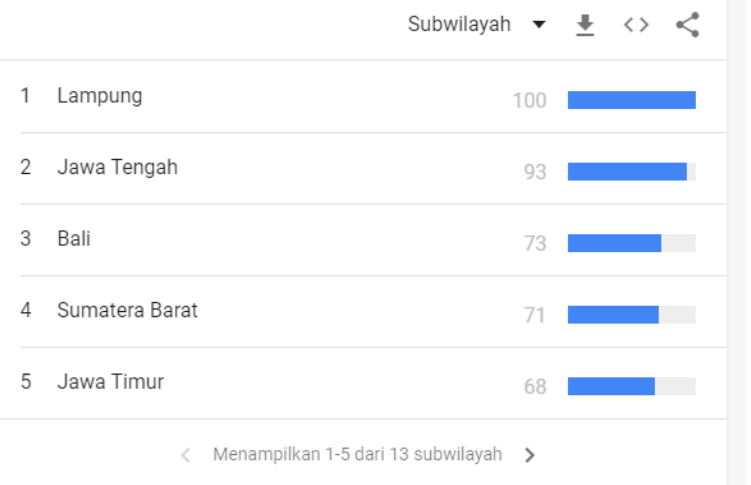

\section{Gambar 2. Presentase Minat Terhadap Komik Pendidikan Menurut Subwilayah di Indonesia}

Dari dari data yang dikutip dari Google Trends diatas, menunjukan presentase beberapa wilayah di Indonesia yang memiliki minat paling tinggi terhadap komik pendidikan. Presentase tertinggi diperoleh Lampung dengan jumlah 100, diikuti oleh Jawa Tengah dengan jumlah 93, Bali dengan jumlah 73, Sumatera Barat dengan jumlah 71, dan Jawa Timur dengan jumlah 68.

Penggunaan komik pendidikan sebagai media pembelajaran di Indonesia pada saat ini sudah mulai berkembang. Pasalnya diberbagai wilayah dan berbagai jenjang pendidikan di Indonesia sudah mulai melakukan pengembangan media komik pembelajaran, sebagai sumber belajar mereka. Dengan demikian komik pendidikan di Indonesia akan semakin popular dan menjadi salah satu media yang dapat menanggulangi masalah kebosanan siswa dalam belajar.

Penelitian Andriani dkk (2014) menemukan hasil dari 197 siswa sebagai objek penelitian, sebesar 68.78\% memiliki skor kurang dalam pembelajaran sejarah berdasarkan Tingkat Capaian Responden (TCR). Hal itu disebabkan karena pembelajaran sejarah yang dinilai membosankan sehingga hasil dari pembelajaran sejarah menjadi tidak efektif.

Dalam studinya tentang "Menggunakan Komik dalam Pengajaran Ilmu Sosial di Sekolah Dasar" (Durualp, 2006) sampai pada kesimpulan bahwa keberhasilan dalam pembelajaran telah meningkat dengan menggunakan komik saat mempelajari unit "Kehidupan Demokratik". Dalam studinya tentang "Pengaruh Menggunakan Bahan Komik terhadap Keberhasilan Siswa dalam Mengajar Sejarah" (KÕlÕnç, 2006) mengajarkan unit "Perang Dunia I" dengan menggunakan metode-metode pengajaran tradisional untuk kelompok kontrol, dan dengan menggunakan komik untuk kelompok eksperimen, dapat disimpulkan bahwa pengajaran berdasarkan komik lebih sukses daripada metode pengajaran tradisional.

Dalam studinya untuk mengetahui pengaruh komik terhadap pengajaran ekspresi tertulis dalam Bahasa dan Sastra Turki. (Üstün, 2007) memberikan keterangan bahwa, mengajar dengan menggunakan komik dapat meningkatkan keberhasilan dalam belajar. Dalam penelitian lain yang dilakukan oleh (Durmaz ,2007). itu bertujuan untuk menganalisis pengaruh gagasan komik pada keberhasilan siswa pada unit "Divisi Sel Mitosis-Meiosis" dalam pengajaran sains konstruktivis.

Komik dapat memberikan contoh konstruksi pendidikan dan psikologis dan memperluas pembelajaran siswa. Dalam banyak buku ajar psikologi pendidikan, komik sering digunakan untuk 
menjelaskan atau menggambarkan sebuah konsep. Misalnya, dalam Ormrod's (2011) Psikologi Pendidikan: Pembelajar Pembangunan (edisi ke-7), ia memasukkan 11 komik yang termasuk Calvin dan Hobbes, Doonesbury, Sisi Jauh dan Dalam Pemutih. Dalam Santrock's (2009) Educational Psychology, ia menggunakan 28 komik termasuk Peanuts dan Frank and Earnest, atau dari koleksi kartun, seperti The New Yorker atau Phi Delta Kappan.

Demikian juga, penulis psikologi pendidikan lainnya termasuk Woolfolk (2010) dan Slavin (2012) menggunakan komik dalam teks mereka untuk meningkatkan minat siswa dan menggambarkan konsep pendidikan dengan cara yang lucu. Kesimpulannya, ditemukan bahwa metode pengajaran menggunakan gagasan komik lebih efektif daripada metode pengajaran tradisional. Hasil penelitian ini sejalan dengan hasil penelitian di atas. Seperti riset (Keogh dan Naylor ,1999) menyebutkan komik meningkatkan konsentrasi siswa pada pelajaran yang memiliki ketidakmampuan belajar, meningkatkan partisipasi dalam diskusi selama pelajaran, dan menempatkan siswa dalam tindakan untuk meneliti kebenaran cara berpikir yang disajikan dalam komik.

Selain itu, dalam studinya tentang "Penelitian pada Kegunaan Komik Teknik dalam Pelatihan Sains dan Lingkungan". (Özalp ,2006) telah menyimpulkan bahwa menggunakan komik dalam metode pelatihan dapat meningkatkan keberhasilan siswa dan meningkatkan pendekatan siswa terhadap pelajaran dengan cara yang positif. Hasil yang sama telah diperoleh dalam penelitian ini juga, dan dalam wawancara yang dilakukan dengan siswa terlihat bahwa sikap siswa adalah positif untuk pelajaran.

Komik dapat digunakan untuk membangun konteks afektif positif dan minat pada teori pengajaran dan pembelajaran, dan mendorong siswa untuk terus merefleksikan dan berpikir kritis tentang praktik terbaik untuk pembelajaran dan keterlibatan. Rasa senang yang meningkat di kelas dan penghargaan untuk guru yang menggunakan humor di kelas telah ditemukan dalam studi eksperimental (Nagata, 1999; Ziv, 1988). Ziv, Eli, dan Moris (1986) juga melaporkan bahwa siswa memiliki apresiasi yang berbeda untuk profesor yang menggunakan humor.

Menurut Martin (2007), penelitian tentang penggunaan humor yang sesuai di kelas menunjukkan bahwa "Guru di kelas terkait dengan evaluasi guru yang lebih positif, kenikmatan kursus yang lebih besar dan pembelajaran yang lebih dirasakan oleh siswa" (hal. 359). Meskipun penelitian ini umumnya mendukung hasil yang ditemukan sebelumnya, penelitian lebih lanjut harus dilakukan untuk menyelidiki apakah penggunaan metode lain, termasuk penggunaan literatur anakanak, memiliki efek yang sama.

Penelitian empiris menggunakan media komik dan novel grafis dalam pendidikan telah lama dimulai sejak tahun 1940-an (Hutchinson, 1949). Namun yang mengherankan sebuah studi yang lebih baru dilakukan oleh Cooper, Nesmith, dan Schwarz (2011), menginformasikan meskipun pendidik pada saat ini sudah berhati- hati dalam menggunakan media tersebut, namun banyak dari pengguna mengakui hanya sebagian kecil yang berhasil dalam penggunaan komik dan novel grafis untuk tujuan akademik.

Terlepas dari hasil riset behwa komik pendidikan yang dianggap menyenangkan, Melor, Hadi, dan Amin (2012) juga mengeluarkan sebuah pernyataan, bahwa penerapan aktivitas berbasis komik 
dalambentuk web tidaklah praktis, karena keterbatasan waktu dan akses internet. Selain itu fase yang berlarut- larut dalam menyusun foto dan gambar untuk digunakan dalam perangkat penulisan dan dibutuhkannya waktu untuk mempelajari perangkat lunak itu sendiri juga berkontribusi terhadap ketidaknyamanan ini. Karena narasi merupakan aspek penting dari novel grafis, desain untuk implementasi mendongeng dalam alat penulisan komik pendidikan harus dipertimbangkan. Kontrol tema selalu menjadi tantangan ketika aplikasi yang digunakan sebagai media penceritaan terbatas pada plot pra-tetap dan komposisi acara longgar (Schoenau-Fog, Bruni, Khalil, \& Faizi, 2013).

Membuat sebuah komik pembelajaran memang tidak mudah. Diperlukan sebuah strategi dan tips yang efektif untuk dapat menghasilkan sebuah komik pembelajaran yang baik. Kelompok penelitian di Universite de La Rochelle membangun basis data komik (C. Guerin, C. Rigaud, A. Mercier, F. Ammar- Boudjelal, K. Betet, ' A. Bouju, J.-C. Burie, G. Louis, J.-M. Ogier, and A. Revel, 2013) dan menganalisis struktur elemen visual dalam sebuah halaman untuk memahami konten komik secara semantik (C. Rigaud, C. Guerin, D. Karatzas, J.-C. Burie, and J.-M. Ogier, 2015).

Leksem dan norma budaya terkadang lebih sulit untuk dioleh dari teks sumber ke dalam teks target, dan ada kendala teknis tentang ruang balon dalam komik. Penerjemah siswa dapat memberikan catatan penjelasan di bilah samping dalam komik untuk membantu pembaca lebih memahami makna kata-kata dan konsep (Prough, 2010). Strategi utama dalam masalah ini akan terdiri dari membagi kalimat yang lebih panjang menjadi segmen yang lebih kecil, terkait dengan konten. Sehingga membuat ataupun menyusun sebuah komik pembelajaran dibutuhkan strategi dan teknik yang matang.

\section{SIMPULAN}

Berdasarkan artikel yang telah penulis telaah dapat disimpulkan bahwa penggunaan media komik berbasis web atau komik digital online sangat efektif apabila digunakan dalam pebelajaran sejarah. Namun dalam penggunaanya ada beberapa hal yang harus diperhatikan seperti, audien yang dituju, gambar yang menarik, bahasa yang digunakan, waktu untuk membaca dan koneksi internet yang memadahi. Sehingga dapat menjadikan komik tidak membosankan, dapat menimbulkan ketertarikan bagi siswa untuk membaca, mudah diingat serta yang terpenting dapat tercapainya tujuan pembelajaran sejarah.

Komik berbasis web dalam praktiknya memang dapat digunakan sebagai media pendukung dalam pembelajaran sejarah bagi siswa. Namun untuk kedepannya sebaiknya perlu dilakukan penelitian dan pengkajian lebih lanjut terkait penggunaan media tersebut. Hal ini ditujukan untuk mengetahui kualitas, keefektifan, dan kemampuan sekolah untuk menggunakan media komik berbasis web dalam pembelajaran sejarah di SMA. 


\section{DAFTAR REFERENSI}

Analysis, A., \& Schools, E. (n.d.). 학습만화에 대한 초등학생과 학부모의 인식 분석 연구. 227-246.

Kerneža, M., \& Košir, K. (2016). Comics as a literary-didactic method and their use for reducing gender differences in reading literacy at the primary level of education. Center for Educational Policy Studies Journal, 6(2), 125-149.

Rota, G., \& Izquierdo, J. (2003). "Comics" as a tool for teaching biotechnology in primary schools. Electronic issue2- fulltext-10
Journal
of Biotechnology, 6(2), 8-12.
https://doi.org/10.2225/vol6-

Ozdemir, E. (2017). Comics in Modern Physics: Learning Blackbody Radiation through Quasi-History of Physics. Studies in Educational Research and Development Volume, $\quad 1(1), \quad 41-59$. http://ezproxy.lib.uconn.edu/login?url=http s://search.ebscohost.com/login.aspx?direct $=$ true $\& \mathrm{db}=$ eric $\& A N=E D 579152 \&$ site $=$ eho st-live

Fenske, F., Klee, A., \& Lutter, A. (2000). Concept-Cartoons as a Tool to Evoke and Analyze Pupils Judgments in Social Science Education. 10(3), 46-52.

Machemy, J., \& Bousquet, B. (2015). Conception of comics dedicated to optics learning. Education and Training in Optics and Photonics: ETOP 2015, 9793, 97931F. https://doi.org/10.1117/12.2223111

McLaughlin, R., \& Bell, R. (2002). Teaching and learning. Emergency Medicine Journal, 19(4)， 375-376. https://doi.org/10.7591/9781501706318- 009

Nguyen, N. Van, Rigaud, C., \& Burie, J. C. (2018). Digital comics image indexing based on deep learning. Journal of Imaging, 4(7). https://doi.org/10.3390/jimaging4070089

Wahyuningtyas, C. A. (2017). Efektivitas Penggunaan Media Pembelajaran Komik Materi Pembelajaran Peristiwa Sekitar Proklamasi Pada Hasil Belajar Sejarah Siswa Kelas XII IPS SMAN 1 Ngemplak, Sleman Tahun Ajaran 2016/2017. 209-217.

Oc, E. (2015). Engendering Learning Participation of Pupils By Use of Comics and Cartoons in Teaching. November.

Farah, N. A., Syamsul, B. Z., \& Norshuhada, S. (2014). Exploring Digital Comics as an Edutainment Tool: An Overview. Knowledge Management International Conference 2014, August, 589-594.

Chung, B. S., Kim, J., \& Chung, M. S. (2017). Integrated Comics and Visible Korean Movies for Laypeople's Learning of Systemic Anatomy. International Journal of Morphology, 35(3), 883-887. https://doi.org/10.4067/s0717- 95022017000300014

Nugroho, S., \& Shodikin, A. (2018). Keefektifan Pembelajaran Student Teams Achievement Division ( Stad ) Berbantuan Komik ( Learning Effectiveness of Student Teams Achievement. Jurnal Matematika Dan Pendidikan Matematika, 3(1), 22-32.

Aisyah, R., Zakiyah, I. A., Farida, I., \& Ramdhani, M. A. (2017). Learning Crude Oil by Using Scientific Literacy Comics. Journal of Physics: Conference Series, 895(1).https://doi.org/10.1088/1742- 6596/895/1/012011

Ratnawuri, T. (2016). Pemanfaatan Komik Strip Sebagai Media Pembelajaran Mahasiswa Pendidikan Ekonomi Um Metro. PROMOSI (Jurnal Pendidikan Ekonomi), 4(2), 8-12. https://doi.org/10.24127/ja.v4i2.632

Printina, B. I. (2019). Pemanfaatan Media Komik Digital Melalui Unsur PPR (Paradigma Pedagogi Reflektif) Pada Matakuliah Sejarah Asia Barat Modern. Jurnal Pendidikan Sejarah, 8(1), 1-13. https://doi.org/10.21009/jps.081.01

Marwatoen, F. (2015). Pengaruh Media Presentasi dan Komik dalam Pembelajaran Biologi terhadap Hasil Belajar ditinjau dari Motivasi Siswa. Prisma Sains : Jurnal Pengkajian Ilmu Dan Pembelajaran Matematika Dan IPA IKIP Mataram, 3(2), 71. https://doi.org/10.33394/j-ps.v3i2.976

Prasetyono, A. E., Amsia, T., \& Sri Ekwandari, Y. (2015). Pengaruh Penggunaan Media Komik Terhadap Peningkatan Hasil Belajar Sejarah. PESAGI : Jurnal Pendidikan Dan Penelitian Sejarah, 3(6).

Untuk, S., Yang, P., \& Strategi, M. (2012). Pengembangan Media Komik Bergambar Materi Sistem Saraf Untuk Pembelajaran Yang Menggunakan Strategi Pq4R. Journal of Innovative Science Education, 1(1).

Pendidikan, J., \& Volume, S. (2018). Research \& Development ). 5, 190-201.

Fatimatus, I., Utariyanti, Z., Wahyuni, S., \& Zaenab, S. (2015). PENGEMBANGAN MEDIA PEMBELAJARAN BERBASIS KOMIK DALAM MATERI SISTEM PERNAPASAN PADA SISWA KELAS VIII MTS MUHAMMADIYAH 1 MALANG. 1(3),2442-3750. 
Irwandani, I., \& Juariyah, S. (2016). Pengembangan Media Pembelajaran Berupa Komik Fisika Berbantuan Sosial Media Instagram sebagai Alternatif Pembelajaran. Jurnal Ilmiah Pendidikan Fisika Al-Biruni, 5(1), 33. https://doi.org/10.24042/jpifalbiruni.v5i1.1 03

Mudlaafar, K., Setiawan, E., \& Muflih, I. K. Al. (2019). PENGEMBANGAN MEDIA PEMBELAJARAN KOMIK SEJARAH BERWAKTU ( KOMIK RATU ) SEBAGAI ALTERNATIF PEMBELAJARAN UNTUK SISWA KELAS 5 SEKOLAH DASAR ( Kajian

Materi: Tema 7 , Sub Tema 2 , Peristiwa Kebangsaan Seputar Proklamasi Kemerdekaan ) Abstrak. Jurnal Inventa, III(1), 62-70.

Payakumbuh, D. I. (2016). PERANCANGAN KOMIK SEJARAH JEMBATAN RATAPAN IBU DI PAYAKUMBUH Febri Ferdian.

Matsui, Y., Ito, K., Aramaki, Y., Fujimoto, A., Ogawa, T., Yamasaki, T., \& Aizawa, K (2017). Sketch-based manga retrieval using manga109 dataset. Multimedia Tools and Applications, 76(20), 21811-21838. https://doi.org/10.1007/s11042-016-4020-z

Damopolii, I., \& Rahman, S. R. (2019). The effect of STAD learning model and science comics on cognitive students achievement. Journal of Physics: Conference Series, 1157(2). https://doi.org/10.1088/1742$6596 / 1157 / 2 / 022008$

Topkaya, Y. (2016). The impact of instructional comics on the cognitive and affective learning about environmental problems. Egitim ve Bilim, 41(187), 199-219. https://doi.org/10.15390/EB.2016.5713

Tuncel, G., \& Ayva, Ö. (2010). The utilization of comics in the teaching of the "human rights" concept. Procedia - Social and Behavioral Sciences, $\quad 2(2), \quad 1447-1451$. https://doi.org/10.1016/j.sbspro.2010.03.21 6

Furuhata-turner, H. (2016). Use of Comics Manga as a Learning Tool to Teach Translation of Japanese. The Journal of Language Learning and Teaching, 3(2), 72-83.

YUNUS, M. M. D., SALEHI, H., TARMIZI, A.,\& SYED, S. F. (2011). Using Digital Comics in Teaching ESL Writing. Proceedings of the 2nd International Conference on Arts and Culture (ICAC 11), 53-58. 